\title{
El testamento de Cristóbal García Salmerón: un documento inédito de un pintor olvidado
}

\author{
The Testament of Cristóbal García Salmerón: an Unpublished \\ Document of a Forgotten Painter
}

\section{Sonia Casal Valencia ${ }^{1}$}

Universidade de Santiago de Compostela

\begin{abstract}
Resumen: Cristóbal García Salmerón fue un pintor barroco que desarrolló buena parte de su carrera en su Cuenca natal. Hacia mediados del siglo XVII, aunque en fecha incierta, se traslada a Madrid donde reside hasta su muerte, siendo su testamento el último de los numerosos documentos que se han hallado sobre la vida de este artista en la villa. Este interesante documento, fechado el 22 de octubre de 1673, permite conocer parte del círculo familiar y social de García Salmerón, así como constatar que esta última etapa de su vida estuvo marcada por las deudas y la disminución de su patrimonio.
\end{abstract}

Palabras clave: Cristóbal García Salmerón; pintor; testamento; Madrid; siglo XVII; Teresa Romero aprendiz de pintora.

Abstract: Cristóbal García Salmerón was a Baroque painter who spent much of his career in his native Cuenca. Towards the middle of the 17th century, although at an uncertain date, he moved to Madrid, where he lived until his death, being his will the last of the numerous documents that have been found on the life of this artist in the town. This interesting document, dated 22 October 1673, reveals part of García Salmerón's family and social circle, as well as showing that this last stage of his life was marked by debts and the diminution of his estate.

Keywords : Cristóbal García Salmerón ; painter ; testament ; Madrid ; $17^{\text {th }}$ century; Teresa Romero painter's apprentice.

1 (ㄱ) http://orcid.org/0000-0002-0967-5819

(C) 2021 Philostrato. Revista de Historia y Arte 


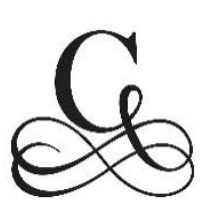

ristóbal García Salmerón (Cuenca, 1603 - Madrid, 1673) ha sido, historiográficamente, un pintor relegado a un segundo plano no habiendo estudios profundos y completos en torno a su biografía o su catálogo artístico. Son escasos los autores que lo citan y, quienes lo hacen, lo realizan de una manera escueta $y$, en numerosas ocasiones, con errores que se perpetúan en el tiempo y que hacen pensar en el poco o nulo interés que ha suscitado este artista.

No obstante, fue un pintor de cierta importancia y calidad a la vista de los estudiosos que dan cuenta de él. El tratadista Antonio Palomino fue el que recogió los primeros datos sobre la biografía y el catálogo de este artista en su obra El Museo Pictórico y Escala Óptica publicada en 1724, varias décadas después del fallecimiento del pintor, afirmando que García Salmerón fue natural de la ciudad de Cuenca y discípulo del murciano Pedro Orrente, sin aportar ningún tipo de documento al respecto. Continúa declarando que en su ciudad natal llevó a cabo diferentes obras, como una fiesta de toros con su propio autorretrato pintada para el rey Felipe IV con motivo del nacimiento del futuro monarca Carlos $\mathrm{II}^{2}$, trasladándose posteriormente a la Corte donde realizaría un Buen Pastor para el Convento del Carmen Calzado de Madrid y fallecería en dicha villa hacia 1666, a la edad de 63 años.

Este último dato relativo a la fecha de muerte del pintor conquense ha sido asumido, repetido y perpetuado por todos los estudiosos y críticos de arte que tras Palomino se interesaron por Cristóbal García Salmerón, tales como Antonio Ponz, Ceán Bermúdez, Bermejo Díez o Angulo Íñiguez y Pérez Sánchez, autores estos últimos que trazaron el catálogo más completo de la obra del pintor ${ }^{3}$.

Pese a la importancia del trabajo realizado por Angulo Íñiguez y Pérez Sánchez, siguieron manteniendo el año de 1666 como fecha de muerte de García Salmerón. No será, por tanto, hasta dos décadas más tarde cuando Barrio Moya publique dos documentos importantes sobre el artista fechados en 1668 y 1673, es decir, con posterioridad a su supuesto fallecimiento ${ }^{4}$.

En el primero de ellos, datado el día 17 de febrero de 1668, García Salmerón, como vecino de Madrid, da un poder a un habitante de Cuenca para que en su nombre pueda vender unas casas que él tenía en la calle de San Juan de su ciudad natal. En el segundo, fechado el 1 de marzo de 1673, y a la edad de 70 años, el artista es llamado para tasar las pinturas de un clérigo, Don Luis Tofino, fallecido en Madrid. Estos dos documentos permiten

\footnotetext{
2 Antonio Palomino de Castro y Velasco, El Museo Pictórico y Escala Óptica, (Madrid: M. Aguilar Editor, 1947), pp. 942-943. La referencia al nacimiento de Carlos II que Palomino hace es errónea, puesto que la fiesta de toros tuvo lugar en el año 1642, es decir, casi dos décadas antes del alumbramiento del futuro monarca.

${ }^{3}$ Diego Angulo Íñiguez y Alfonso E. Pérez Sánchez, Historia de la pintura española. Escuela toledana de la primera mitad del siglo XVII, (Madrid: Instituto Diego Velázquez, 1972), pp. 364-371.

${ }^{4}$ José Luis Barrio Moya, "Algunas noticias sobre Cristóbal García Salmerón, pintor conquense del siglo XVII", Tiempo y espacio en el arte: homenaje al profesor Antonio Bonet Correa, vol. II, (1994), pp. 901910.
} 
corregir la errónea fecha de muerte perpetuada durante más de doscientos años y situarla, por tanto, después del mes de marzo de 1673.

Los nuevos datos que se dan a conocer en esta publicación se refieren, precisamente, al testamento que Cristóbal García Salmerón otorga el día 22 de octubre de 1673 ante el escribano Sebastián Carrillo, siendo testigos Martín de Carate, Andrés Pardo, Juan Mateo, Antonio de Chindurca y Cristóbal Romero, todos residentes en Madrid (Doc. 1$)^{5}$.

A lo largo del citado documento se aporta información muy valiosa y de muy diversos asuntos que conviene analizar para conocer datos relativos a la desconocida familia del pintor y a la situación y relaciones que tenía García Salmerón en sus últimos días.

En primer lugar, el pintor confirma en su testamento que era natural de Cuenca e hijo legítimo de los fallecidos Cristóbal García y Juana de Salmerón, de los que se tiene un total desconocimiento. El único escrito que se puede afirmar como verídico relacionado con los padres de Cristóbal García Salmerón es el testamento de su madre, expedido en agosto del año $1638^{6}$. En él se advierte que, en esta fecha, Juana de Salmerón era viuda de Francisco Sanz. Este dato revela que su matrimonio con Cristóbal García había acabado y, en el siglo XVII, un enlace de estas características solo podría finalizar con la muerte de uno de los cónyuges, por lo que el padre del pintor habría fallecido varios años antes de este testamento, pues la protagonista había tenido tiempo de casarse y enviudar de nuevo.

Seguidamente se pone de manifiesto que el propio Francisco Sanz había dejado una cláusula en su testamento por el cual pedía que se le diesen cuarenta ducados a Luisa de Almodóvar, de quien Juana de Salmerón indica que es "mi nieta hija de ju de almodobar difunto y de fran"a de Saldaña"7. Junto a Luisa añade otras dos nietas más, Juana y Francisca de Almodóvar. Esta circunstancia es de suma importancia ya que la no coincidencia de apellidos entre el difunto marido de Juana de Salmerón y los padres de sus nietas indica que, al menos, contrajo matrimonio una tercera vez.

Este dato proporciona una nueva idea de familia del pintor pues, al menos, tuvo una hermana por parte de madre y tres sobrinas, de las que se desconoce el grado de proximidad y afecto que pudieron llegar a alcanzar.

Finalmente, en el citado testamento de Juana de Salmerón también se indica que, para que se pudiese cumplir y pagar todo lo que en él estaba contenido, la susodicha nombró como sus albaceas y testamentarios a su hijo, Cristóbal García, y a su nuera, Juana Millán, para que se hiciesen cargo

\footnotetext{
${ }^{5}$ Archivo Histórico de Protocolos de Madrid (en adelante AHPM), T. 9301. Sebastián Carrillo, 1673-1677, fol. 213-216.

${ }^{6}$ Archivo Histórico Provincial de Cuenca (en adelante AHPC), P-1021, Juan de Solera, 1636-1638, fol. 204205v.

7 AHPC, P-1021, Juan de Solera, 1636-1638, fol. 204v.
} 
de sus bienes y los pudiesen vender y rematar en pública almoneda o fuera de ella durante todo el tiempo que fuese necesario.

A raíz de este último apunte se puede afirmar que el pintor contrajo matrimonio con una mujer llamada Juana Millán de la cual se conserva carta de dote fechada en enero de $1625^{\circ}$. En este documento, también inédito, se deriva una situación económica muy favorable por parte de la familia de la contrayente, de la que el pintor parece beneficiarse pues obtiene numerosos objetos, bienes, dinero y hasta una vivienda, que alcanzan una tasación superior a los 6000 reales.

Además, gracias a otros documentos hallados a lo largo de la investigación, se ha podido saber que de este matrimonio nacen, al menos, dos hijas, María y Mariana ${ }^{9}$, siendo nombrada la primera como única y heredera universal en el testamento de su padre, ya que la restante habría fallecido unos años antes, pues se han hallado sus últimas voluntades, fechadas en el año $1664^{10}$.

En cuanto a María García Salmerón, como la citan en el testamento del pintor, se advierte que está casada con Diego de Scals y Salcedo, en estos momentos oidor criminal de la Real Audiencia de Valencia, pero cuyos apellidos sitúan a este personaje dentro de uno de los linajes más importantes del momento, pues la casa de Scals "es de Nobleza, y militares hazañas", una familia de soldados y capitanes que se labraron gran fama a costa de "sus azeros teñidos en la sangre de los enemigos de estas coronas"11.

El origen de esta estirpe tiene lugar con Laurencio de Scals quien, aunque natural de Verona e hijo del príncipe y duque del lugar, acudió a servir con su hermano a Jaime I de Aragón para la conquista de Mallorca en 1228. Una vez establecidos en la península y habiendo pasado varias generaciones y siglos, nace en el año 1597, en Cocentaina, Onofre Diego, quedando como único heredero de un patrimonio ya destrozado por las enajenaciones y particiones. Además, va a ser desheredado al contraer matrimonio "sin licencia de sus padres" 12 en 1620, yéndose, de esta forma, a vivir a Cuenca donde se dedica a la poesía, las matemáticas, las letras y la jurisdicción. Muere en esta ciudad en 1657 haciendo testamento el día 5 de octubre ${ }^{13}$.

En esta escritura se advierte que, del matrimonio con su mujer, Andrea del Castillo, nacieron diferentes hijos entre los que se encuentra "Don Diego de

\footnotetext{
${ }^{8}$ AHPC, P-920, Francisco de Salazar, 1625, fol. 20-21v.

${ }_{9}^{9}$ AHPM, T. 4215, Martín de Badarán, 1655-1666, fol. 754-754v. El 11 de abril de 1663, Cristóbal García Salmerón otorga un poder a Nicolás de Cuéllar, procurador del número de la ciudad de Cuenca, para que en su nombre pueda acudir ante cualquier juez y justicias de la localidad para hacer pedimento ante ellos de cómo María y Mariana, hijas legítimas de su matrimonio con Juana Millán, ya fallecida en este momento, eran parientas del racionero Tomás del Castillo y, de esta forma, se pida la renta que el citado racionero dio para parientas de su linaje y obras pías fundadas en dicha localidad.

${ }^{10}$ AHPM, T. 9907, Simón Navarro, 1664-1667, fol. 38-39.

${ }^{11}$ Diego de Scals y Salcedo, Origen, casa y familia de Scals o de la Scala, heredada en las montañas de el reyno de Valencia..., (Valencia: Francisco Mestre, 1681), s.f.

12 Diego de Scals y Salcedo, Zenotafio gentilicio, y parentación honoraria de glorias militares al árbol genealógico y chronologico historiado de la Casa de Scals..., (Valencia: Francisco Mestre, 1681), pp. 3334.

${ }^{13}$ AHPC, P-1071, Alonso González, 1657, fol. 736-737v.
} 
Salcedo que reside en la ciưd de Salam ca"14. En esta localidad es donde el futuro yerno de García Salmerón se gradúa en la facultad de Derecho de las dos jurisprudencias, civil y canónica, opositando a cátedra de leyes y realizando diversos escritos sobre estos temas. Además, estando todavía en Salamanca, fue llamado por Felipe IV para servir en el Oficio de Lugarteniente de Corregidor y Alcalde Mayor de la ciudad "para quietar tantos disturbios, y alborotos"15. No obstante, compaginó esta ardua labor con la de lector de oposición durante tres años.

Gracias a esto, en 1669, se le concedió la plaza civil en la Real Audiencia de Cerdeña dándole el tratamiento de noble, donde sirvió por tres años. Pasado este tiempo, en 1672, consiguió la plaza de Oidor Criminal en la ciudad y reino de Valencia, cargo reflejado en el testamento de Cristóbal García Salmerón.

Entre sus diversos trabajos, pasó un lapso de tiempo en Madrid donde pudo contraer matrimonio, en 1665, con María Salmerón, encontrándose Diego de Scals y Salcedo en una de las mejores etapas profesionales de su vida y, por lo tanto, cabría pensar que, en un período económico destacable, consiguiendo el pintor para su hija un enlace muy beneficioso.

De esta unión nace su primogénito el 17 de mayo de 1666, teniendo lugar el bautismo solo diez días más tarde en la madrileña parroquia de San Martín donde el teniente de cura de la misma, fray Pedro de León, bautiza a Diego Joseph Félix. El niño tuvo por padrino a Cristóbal García Salmerón, su abuelo, y por madrina, a María Salcedo, por cuyo apellido habría que suponer es familiar del padre de la criatura. Además, según una obra escrita por el propio oidor criminal de la Real Audiencia de Valencia, Diego de Scals y María Salmerón fueron padres por segunda vez de una niña llamada Margarita, de la que no aporta fecha de su nacimiento ${ }^{16}$.

Por tanto, como se ha visto, son pocas las alusiones directas que Cristóbal García Salmerón hace de su familia en su testamento, pues solo cita a sus padres y al matrimonio formado por su hija María y su yerno. No obstante, la información obtenida paralelamente en esta investigación permite perfilar de manera más precisa parte de su árbol genealógico y conocer que, en fechas próximas a su muerte, no se encontraba rodeado de ella.

Continuando con este valioso documento, el pintor afirma que, en el momento de testar, se encontraba enfermo en la cama, pero en "buen juicio memoria y entendim ${ }^{\text {ton}} 17$, por lo que pudo otorgar su última voluntad haciendo alusión a las siguientes cuestiones.

En primer lugar, encomendando su alma a Dios, pidió que su cuerpo fuera sepultado en el convento de Nuestra Señora de la Victoria por la devoción

\footnotetext{
${ }^{14}$ AHPC, P-1071, Alonso González, 1657, fol. 737.

${ }^{15}$ De Scals y Salcedo, Zenotafio gentilicio, p. 40.

16 De Scals y Salcedo, Zenotafio gentilicio, p. 45

17 AHPM, T. 9301. Sebastián Carrillo, 1673-1677, fol. 213.
} 
que profesaba en ese templo. No obstante, si no se pudiese cumplir esta petición por algún motivo, deja la nueva decisión en manos de sus testamentarios. Asimismo, el pintor deseó que, una vez fallecido, su cuerpo fuera acompañado por la cruz de la parroquia y doce sacerdotes de la misma, delegando la forma de su entierro a elección de sus albaceas aclarando que, "atento los pocos medios en que me allo sea en la misma ponpa y ostentación que pudieran"18. Sin embargo, para el día de su inhumación el artista mandó que se dijera misa cantada por su alma, con diáconos y vigilia, y estando el difunto de cuerpo presente, repitiéndose esas misas de manera frecuente en los altares privilegiados y dando la cuarta parte a la parroquia.

De estas primeras mandas parece derivarse una situación económica de García Salmerón absolutamente paupérrima, sin prácticamente medios que le permitiesen llevar a cabo un entierro con la opulencia que le gustaría, lo que parece indicar una disminución notable en el número de encargos que recibía, hecho quizás vinculado a su avanzada edad y a sus consecuentes pérdidas de precisión en el arte de la pintura, pues el pintor contaba con 70 años, una longevidad destacable en estos tiempos.

Continuando con el testamento, el pintor declara que Antonio de Pedrosa y Molina, vecino de la villa de Madrid, le debe todavía 400 reales de una pintura de El Buen Pastor que hizo en un precio total de 2.000 reales para el convento de Nuestra Señora del Carmen. Pese a esta deuda sustanciosa, es voluntad del artista que con la citada cantidad se hagan ochocientas o novecientas misas por su alma y que el susodicho cumpla con entregar a los herederos del pintor con carta de pago del prelado del convento, porque así lo tienen acordado.

A pesar de que el templo nombrado todavía existe, aunque con la advocación de Carmen y San Luis Obispo, lo cierto es que la pintura en cuestión no está actualmente ubicada en él. Sí se hallaba en esta localización en el siglo XVIII pues Antonio Palomino ya apuntaba que en el Convento del Carmen Calzado de Madrid "ay una Pintura del Buen Pastor, que está en el Claustro chico, junto a la Puerta, que va a la Iglesia, a el lado que mira a el Claustro grande, de mano de Christoval García Salmerón"19. Sin embargo, pese a que el cuadro está firmado, lo cierto es que otro imprescindible autor, Antonio Ponz, señalaba poco tiempo después que el mismo lienzo "lo hizo Andrés de Vargas"20, lo cual podría hacer pensar bien que el escritor no reparó en la rúbrica, bien que el cuadro no se encontraba en el mejor estado de conservación o limpieza para poder apreciarla con claridad. Fuera como fuese, el lienzo en cuestión se conserva actualmente en los depósitos del Museo Nacional del Prado (inv. no P003280) (Fig. 1).

\footnotetext{
18 AHPM, T. 9301. Sebastián Carrillo, 1673-1677, fol. 213v.

${ }^{19}$ Antonio Palomino de Castro y Velasco, Las ciudades, iglesias y conventos en España donde ay obras, de los pintores y estatuarios eminentes españoles, (Londres: Impresso por Henrique Woodfall, 1746), p. 131. ${ }^{20}$ Antonio Ponz, Viage de España, en que se da noticia de las cosas más apreciables, y dignas de saberse, que hay en ella, Tomo V, (Madrid: Joachin Ibarra, 1776), p. 248.
} 


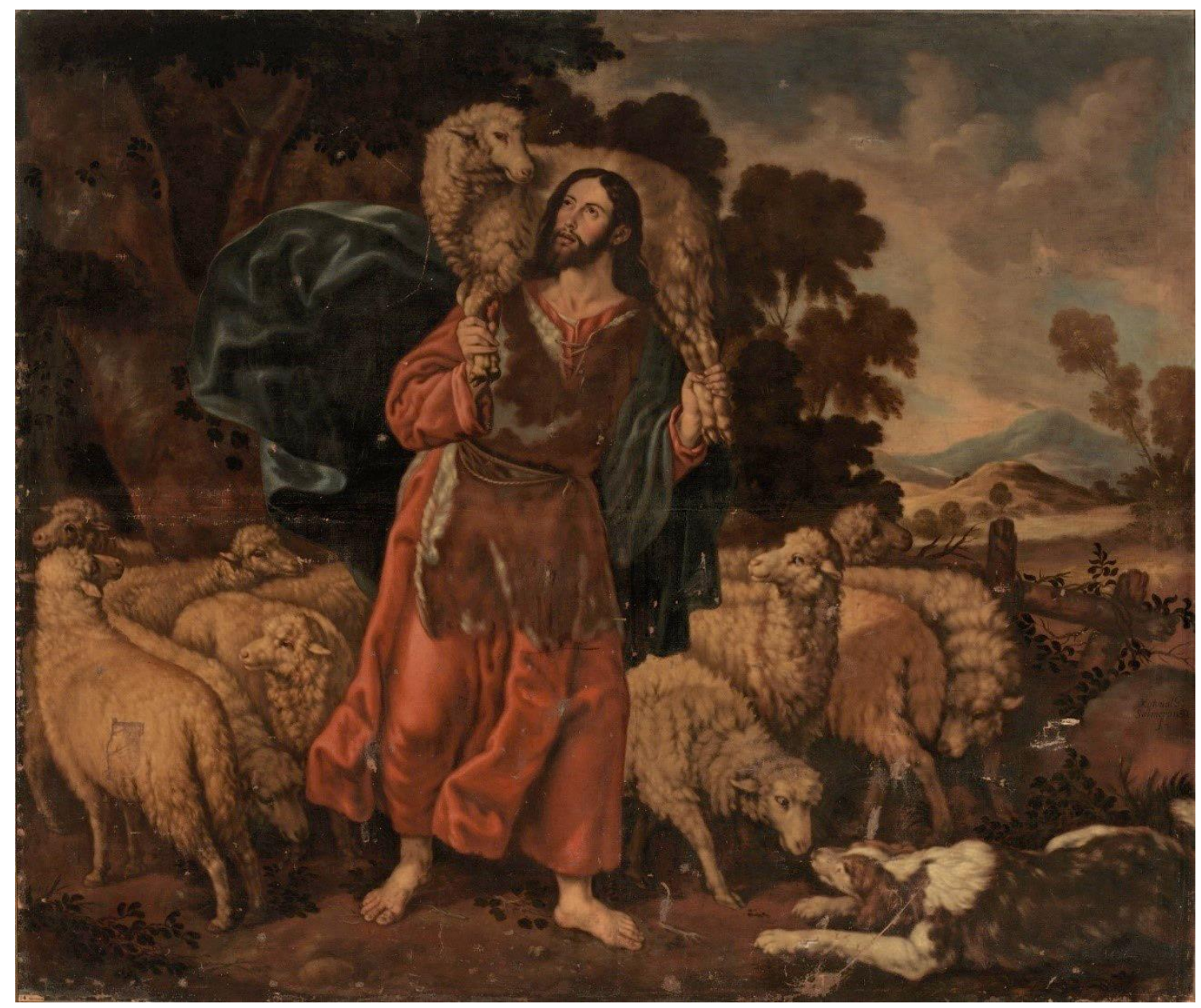

Fig. 1. Cristóbal García Salmerón, El Buen Pastor, Tercer cuarto del siglo XVII. (Óleo sobre lienzo, 228 x 269 cm.) (C) Museo Nacional del Prado, Madrid

Seguidamente, en su testamento, tras destinar cuatro reales a las mandas forzosas, Cristóbal García Salmerón admite deber a Francisco Esteban, "dueño de la cassa que ocupo"21, 250 reales de los alquileres corridos del inmueble hasta el día 6 de octubre del mismo año de 1673, a razón de 900 reales cada año, pidiendo que se pague la citada cantidad y aquellos gastos ocasionados desde el citado día en adelante. Desgraciadamente, no aporta más datos sobre la situación de la morada, desconociendo si estaba ubicada cerca del convento de la Victoria donde quería ser enterrado. Asimismo, tampoco es posible concretar si la relación entre el pintor y su casero era estrictamente contractual o podía existir un vínculo personal previo entre ambos.

Asumida esta deuda con su arrendador, el artista manifiesta deber a un albañil de Cuenca ocho maravedís que manda se paguen al susodicho o a su hermano y, si no pareciesen, se digan misas con esa cantidad. El trabajo desempeñado por este hombre debía estar intrínsecamente relacionado con el arreglo de un inmueble, cabiendo la posibilidad de que se refiriese a las ya

${ }^{21}$ AHPM, T. 9301. Sebastián Carrillo, 1673-1677, fol. 213v. 
vendidas casas que ostentaba el pintor en la conquense calle de San Juan, a su primera morada con su esposa en la calle de la Higuera, otorgada por la familia de esta en la citada carta de dote, o a otra propiedad por el momento desconocida. Estas mismas posibilidades cabría sopesar para otro vecino de Cuenca, Antonio de Muñoz, que debe a García Salmerón 66 maravedís "de tres años que vivió en unas casas que yo tenía en la dha ciu ${ }^{\mathrm{d} / 22}$.

A la deuda de este antiguo arrendatario se suma la de Leandro Ibáñez de Segovia pues, "de resto de un papel"23 de 2.689 reales, le debe todavía 2.137, por lo que manda que se cobre lo que falta. La marcada expresión podría ser algún tipo de pleito ganado por el artista puesto que Leandro de Segovia era "procurador del número desta Villa"24, cargo cuya importancia parece compartir con algunos familiares, probablemente hermanos, pues se han encontrado documentos en los que se pone de manifiesto que Mateo Ibáñez de Segovia es "cavallero de la horden de calatrava"25; Gaspar Ibáñez de Segovia, "cavallero de la orden de alcantra"26; o Baltasar Ibáñez de Segovia y Peralta, "cav ${ }^{\circ}$ de la orden de sant ${ }^{\circ " 27}$, es decir, García Salmerón podría, pese a su delicada situación, mantener contacto o conocer a personajes vinculados con la nobleza y las clases más privilegiadas del momento.

Este frágil momento a nivel económico que estaba padeciendo el pintor es palpable en la deuda que tiene con Francisca de Aro, "mi criada que ha muchos años que me sirve". Admite deberle dinero relacionado con su salario y "otros gastos pequeños que ha echo por $\mathrm{mi}^{28}$, entre los que se encuentran cincuenta ducados de vellón que manda darle de sus bienes para descargo de su conciencia. Asimismo, tras rogar que sus testamentarios ajusten cuentas con ella, el artista indica que se le entregue también la cama en la que su criada duerme, compuesta por "la madera y cordeles, un colchón, un sergon, dos almuadas, dos savanas y dos fracados" 29 .

El hecho de contar o no con servicio era, en gran medida, un reflejo del nivel de vida de los artistas ${ }^{30}$, lo que parece atestiguar que, al menos en el pasado, los posibles de García Salmerón debían ser notables. Se desconoce exactamente el momento en el que el pintor contrata a esta mujer, pero, por el empeño que pone en que se le pague lo debido y se le entregue su cama, parece demostrar que habían forjado una buena relación o que, al menos, la honradez y bondad del artista no le permitía dejarla sin nada.

Por otro lado, el conquense desea que todos los vestidos que quedasen tras su fallecimiento se otorguen a Cristóbal Romero, de quien no se especifica

\footnotetext{
22 AHPM, T. 9301. Sebastián Carrillo, 1673-1677, fol. 214.

${ }^{23}$ AHPM, T. 9301. Sebastián Carrillo, 1673-1677, fol. 214.

${ }^{24}$ AHPM, T. 6944, Melchor Felipe de Baena Parada, 1651, fol. 131.

25 AHPM, T. 6248, Francisco Suárez y Rivera, 1650, fol. 231.

${ }^{26}$ AHPM, T. 9349, Bonifacio de Robles, 1665, fol. 200.

27 AHPM, T. 6543, Pedro de Castro, 1664, fol. 532.

${ }^{28}$ AHPM, T. 9301, Sebastián Carrillo, 1673-1677, fol. 214.

${ }^{29}$ AHPM, T. 9301, Sebastián Carrillo, 1673-1677, fol. 214v-215.

30 Paula Revenga Domínguez, Pintura y sociedad en el Toledo barroco, (Toledo: Monografías 13, 2002), p. 138.
} 
nada más salvo que tiene una hija llamada Teresa a quien García Salmerón quiere que se le den "todos los papeles, libros y estampas que del arte del pintor se hallasen en mi poder", así como "dos piedras de moler colores una grande y otra pequeña", que tendrán que ser entregadas a su padre cuando la susodicha "tome estado" 31 . Además, Teresa Romero debía recibir, también, una pintura de la Virgen María con el Niño y un ángel que, se podría suponer, era de mano del conquense y que se otorgaría como regalo por un más que verosímil vínculo personal y de afecto que se pudiese habido crear entre ambos.

Estas mandas, que se podrían considerar las más curiosas y las que más incertidumbre crean por el desconocimiento de sus protagonistas, proporcionan ciertos datos valiosos que cabría destacar. En primer lugar, García Salmerón todavía contaba, unos días antes de su fallecimiento, con algunos ropajes y vestidos, enseres que podrían relacionarse con un pasado más boyante, que quiere que se entreguen a un hombre, Cristóbal Romero, del que no se ha podido encontrar documentación que pueda aclarar la relación existente entre ambos pero que, en cualquier caso, debía ser muy estrecha.

En segundo lugar, Teresa Romero, hija del aquel hombre, sería la beneficiaria de todos los libros, estampas y papeles relacionados con el oficio y el arte de pintar que habría atesorado el conquense. Este cúmulo de obras no es banal, sino que indica un cierto nivel cultural pues, aunque es común encontrar útiles de trabajo, láminas o bocetos entre los objetos acumulados por los artistas, lo cierto es que es menos habitual hallar libros o tratados artísticos, pues muchos se formaron en talleres modestos, con pocos medios e inquietudes teóricas ${ }^{32}$.

Por otro lado, la misma Teresa Romero recibiría dos piedras de moler colores, de tamaños distintos, un utensilio clave para poder obtener los pigmentos que luego se aplicarían a las superficies correspondientes. Estas herramientas debían ser entregadas a su padre cuando ella "tome estado", una expresión que podría tener varias interpretaciones, como la de casarse o entrar en religión. En cualquier caso, el hecho de otorgar un instrumento tan vinculado al oficio de pintor y que tan útil resultaría "a los jóvenes aspirantes para su futura labor profesional"33, podría hacer pensar en una relación maestro-aprendiz entre el conquense y la citada Teresa Romero, algo que, de ser cierto, sería sorprendente, pues no es habitual una formación en este ámbito y en esta época para las mujeres, especialmente si eran ajenas a la familia del mentor.

Este legado póstumo a una posible aprendiz podría repetirse con la donación de una piedra grande de moler colores que otorga García Salmerón a un varón llamado Juan Mateo del que de nuevo, no se especifica nada más

\footnotetext{
${ }^{31}$ AHPM, T. 9301. Sebastián Carrillo, 1673-1677, fol. 214v.

32 Revenga Domínguez, Pintura y sociedad, p. 161.

33 Revenga Domínguez, Pintura y sociedad, p. 60.
} 
pero que bien podría tratarse de otro alumno a quien quiere premiar con esta útil herramienta, pues es bastante frecuente que, en ausencia de hijos o familiares directos que practiquen la pintura, "sean los discípulos y oficiales quienes hereden todo o parte de lo que constituía el taller"34.

Una vez manifestadas todas las deudas relacionadas con el pintor, de cantidades debidas o a deber, así como haber explicitado una serie de mandas vinculadas con el reparto de alguno de sus bienes, García Salmerón pone como testamentarios de esta escritura a Gil Pardo de Nájera y a Antonio de Pedrosa y Molina para que puedan vender sus posesiones en almoneda ${ }^{35}$ o fuera de ella para poder cumplir y pagar lo estipulado en el testamento.

El segundo albacea citado ya había sido nombrado con anterioridad en este documento pues era la persona que le debía al artista 400 reales de la pintura de El Buen Pastor realizada para el convento de Nuestra Señora del Carmen. El otro testamentario, por su parte, es Gil Pardo de Nájera. Su nombre completo era Gil Antonio Pardo de Nájera y fue marido de Ana de Salcedo ${ }^{36}$, hermana de Diego de Scals y Salcedo, yerno de García Salmerón, es decir, existía un contacto familiar entre testador y albacea que podría manifestar un conocimiento previo entre ambos que diese como resultado el casamiento entre la hija del pintor y el cuñado de su futuro fiduciario.

Por último, García Salmerón admite en su testamento no tener más bienes muebles ni raíces, "tan solam te las pocas alaxas que tengo en mi quarto"37, de las cuales quiere dejar hecha memoria e inventario que quedará en poder de uno de sus albaceas, documento que, desgraciadamente, no ha podido ser encontrado.

Revocando y anulando cualquier otro testamento o codicilio, el pintor otorgó su testamento definitivo ante el escribano Sebastián Carrillo siendo testigos Martín de Carate, Andrés Pardo, Juan Mateo, Antonio de Chindurca y Cristóbal Romero. De estos nombres, tanto Juan Mateo como Cristóbal Romero, aparecían como protagonistas en algunas de las mandas dichas por el pintor. Los restantes son totalmente desconocidos, pudiendo ser amistades de García Salmerón o simplemente testigos llevados por el propio escribano como es el caso de Antonio de Chindurca, pues aparece en multitud de documentos de este amanuense atestiguando lo escrito ${ }^{38}$.

Tras la firma de este testamento (Fig. 2) y debido a la edad del pintor y a la enfermedad que manifestaba padecer, no pudo pasar mucho tiempo hasta su fallecimiento, aunque se desconoce la fecha exacta del mismo. No obstante, tuvo que suceder antes del 16 de enero de 1674, fecha en la que María Salmerón, su hija, otorga un poder a Antonio de Pedrosa para que en

\footnotetext{
34 Alfonso E. Pérez Sánchez, Pintura barroca en España (1600-1750), (Madrid: Cátedra, 2010), p. 20.

35 "La almoneda constituye el primer acto del mercado artístico. (...) Reservados los objetos de los herederos, lo demás se vende para saldar las deudas" en Juan José Martín González, El artista en la sociedad española del siglo XVII, (Madrid: Cátedra, 1993), p. 176.

${ }^{36}$ AHPC, P-1071, Alonso González, 1657, fol. 736-737v.

37 AHPM, T. 9301. Sebastián Carrillo, 1673-1677, fol. 215v.

38 Por ejemplo, en AHPM, T. 9301, Sebastián Carrillo, 1673-1677, fol. 136-136v.
} 
su nombre pueda cobrar una deuda relacionada con su padre. Pese a que este documento, realizado en la ciudad de Valencia ante el escribano Francisco Vicente Navarro, no se ha encontrado, sí se conserva en el Archivo Histórico de Protocolos de Madrid el pago de esa deuda ${ }^{39}$.

En la citada escritura aparece Antonio de Pedrosa como "testamentario ynsolidum"40 del pintor quien, en virtud del poder otorgado por María Salmerón, afirma haber recibido y cobrado de Leandro Ibáñez de Segovia 2.137 reales de vellón del resto de una cédula que le tenía hecha por valor de 2.689 reales, deuda que ya reflejaba el pintor en su testamento por lo que, a 22 de febrero de 1674, consigue ser saldada.

En definitiva, del testamento y últimas voluntades de Cristóbal García Salmerón, se percibe un cambio sustancial en la calidad de su larga vida, pasando de tener una acomodada existencia en su Cuenca natal, con multitud de encargos, pagos y propiedades, a decaer notablemente hasta acabar sus últimos días en una vivienda prácticamente despojada de objetos y con numerosas deudas e impagos.

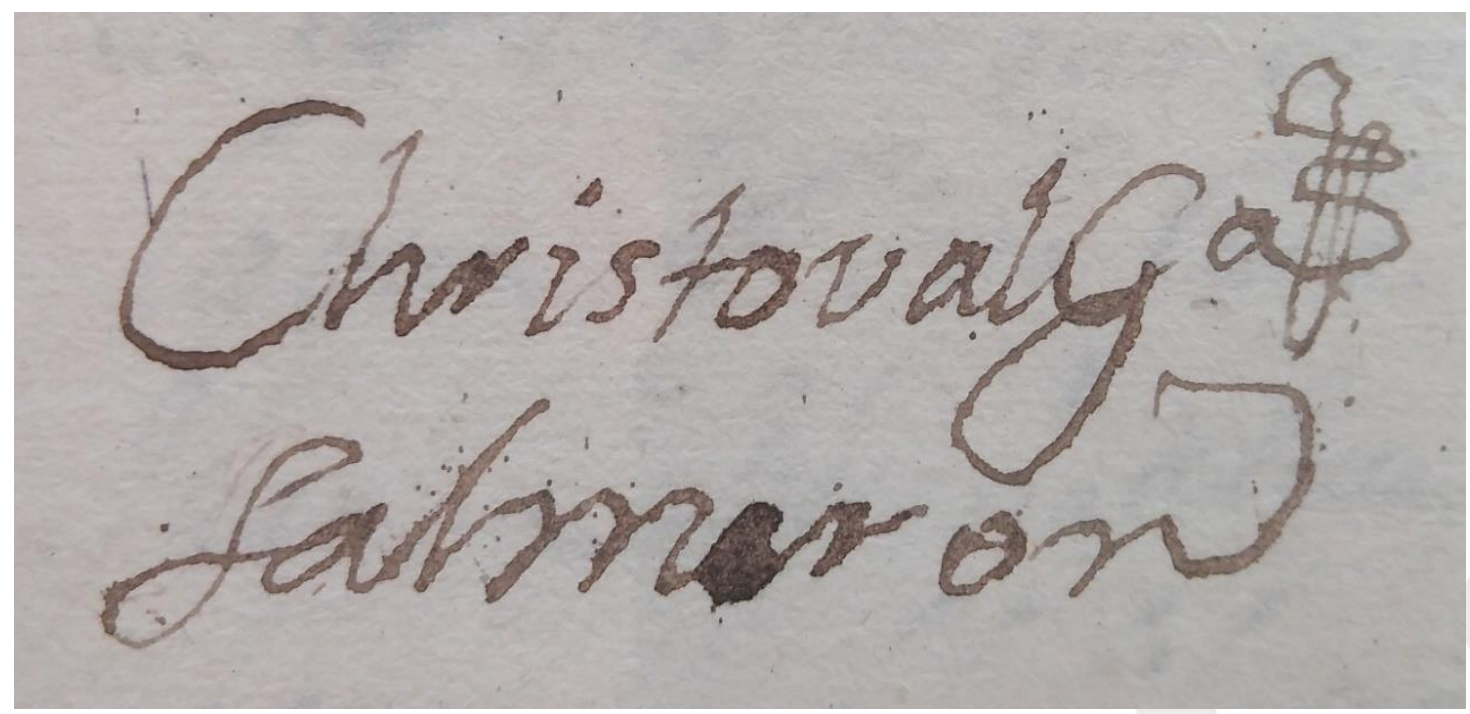

Fig. 2. Detalle de la firma de Cristóbal García Salmerón en su testamento. AHPM, T. 9301. Sebastían Carrillo, 16731677, fol. 216. (C) Foto autora

${ }^{39}$ AHPM, T. 9301, Sebastián Carrillo, 1674, fol. 32-32v.

${ }^{40}$ AHPM, T. 9301, Sebastián Carrillo, 1674, fol. 32. 
Anexo documental:

Archivo Histórico de Protocolos de Madrid (AHPM)

\section{Anexo I}

AHPM, T. 9301. Sebastián Carrillo, 1673-1677, fol. 213-216.

Testamento de Cristóbal García Salmerón

En el nombre de Dios amén sepan quantos esta Carta de testam ${ }^{\text {to }}$ Ultima y postrimera Voluntad viesen como yo Xptoval García Salmerón natural dela Ciu $^{d}$ de Cuenca hijo lex ${ }^{\text {mo }}$ de Xptoval Garcia Seco y Joana de Salmerón su muj difuntos estando enfermo en la cama de la enferm ${ }^{d}$ que Dios nro S. assido servido de me dar y en mi buen juicio memoria y entendim ${ }^{\text {to }}$ natural creyendo como firme $\mathrm{m}$ creo en el misterio de la $\mathrm{ss}^{\mathrm{ma}}$ Trinidad $\mathrm{P}^{\mathrm{a}}$ hijo y espíritu $\mathrm{S}^{\circ}$ tres personas y un solo Dios Verdadero y en todo aquello que tienes y confiera la $\mathrm{s}^{\text {ta }} \mathrm{Ig}^{\mathrm{a}}$ Romana tomando por mi intercesora y abogada de la Reyna de los Ángeles $\mathrm{M}^{\mathrm{a}}$ de Dios y $\mathrm{S}^{\mathrm{a}} \mathrm{Nra}$ y a todos los $\mathrm{S}^{\mathrm{s}}$ y $\mathrm{S}^{\text {as }}$ de la cortte celestial para que yntercedan con nro $\mathrm{S}$. Jesucristo me perdone mis pecados y con esta advocación Divina Intercesión hago y otorgo este mi testam ${ }^{\text {to }}$ Última $\mathrm{y}$ postrimera Voluntad en la forma y manera seg ${ }^{\text {tes }}$.

Lo prim ${ }^{\circ}$ encomiendo mi anima a Dios nro $\mathrm{S}$. que la crio redimio con su preciosa Sangre y Cuerpo a la tierra de que fue formado.

Yten $\mathrm{m}^{\text {do }}$ que $\mathrm{q}^{\text {do }}$ nro $\mathrm{S}$. fuere servido de llevarme desta press ${ }^{\text {te }}$ Vida mi cuerpo sea sepultado en el convento de nra S. de la Vitoria donde tengo devoción y en casso que no pueda ser por algn $^{n}$ accidente lo dexo de Volunt ${ }^{d}$ de mis testam $^{\circ}$ para que sea en la Ig ${ }^{\text {a }}$ Parte y lugar que les pareciera.

$M^{\text {do }}$ que acompañe mi cuerpo la cruz de la Parroquia con doze sacerdotes deella y demás acompañan ${ }^{\text {tes }}$ Y forma de mi entierro también lo dexo a la elección y volunt ${ }^{d}$ de mis testam ${ }^{\circ s}$ y su encargo que atento los pocos medios en que me allo sea en la misma ponpa y ostentación que pudieran.

$\mathrm{m}^{\text {do }}$ que el dia de mi entierro si fuere ora o si no el siguiente se diga por mi anima misa cantada de cuerpo press $^{\text {te }}$ con diaconos y bixilia y de todo se pague la limosna acostumbrada

$\mathrm{m}^{\text {do }}$ que se digan por mi anima frecuentes misas cantadas en los altares privilexiados dando deellas la quarta parte a la parroquia o a la que le toca.

Yten declaro que Don Antonio de Pedrossa y Molina $\mathrm{Vec}^{\circ}$ desta Corte me esta deviendo quatro cientos reales de resto De una Pintura de El Buen Pastor que le hize en precio de dos mill reales para el Conv ${ }^{\text {to }}$ de $n r a s^{a}$ del Carmen, quiero y es mi voluntad que con dicha cantidad se haga decir en el ocho o novecientas missas por mi alma y que cumpla con entregar a mis heros con carta de pago del Prelado Sacristán del dho conv ${ }^{\text {to }}$ porque así lo tengo ajustado con el susodicho. 
$\mathrm{m}^{\text {do }}$ a las $\mathrm{m}^{\text {das }}$ forzossas y acostumbrados quatro $\mathrm{R}^{\mathrm{s}}$ por una vez conque los aparto del dro mis bienes.

Declaro que devo a Fran ${ }^{\mathrm{co}}$ Estevan dueño de la cassa que ocupo ducientos y cinq $^{\text {ta }} \mathrm{R}^{\mathrm{s}}$ de los alquileres corridos de la dha casa asta el día seis deste press ${ }^{\text {te }}$ mes de otb a razón de novecientos Reales cada año. Lo demás que fuere corriendo desde el dho día en delante a dho respeto $\mathrm{m}^{\text {do }}$ se paguen.

Declaro que devo a fulano Lentino alvañil Vecino de Cuenca ocho $\mathrm{m}^{\mathrm{a}} \mathrm{m}^{\mathrm{do}}$ se paguen al susodho o a su her ${ }^{\circ}$ y si no parecieren con la dha cant ${ }^{d}$ se digan de misas.

Declaro que Don Liandro Ibañez de Segovia de resto de un papel de dos mill y seis ${ }^{\circ s}$ y ochenta y nuebe $R^{s}$ que me tiene echo me está deviendo dos mill ciento $y \operatorname{tr}^{\mathrm{a}} \mathrm{y}$ siete $\mathrm{R}^{\mathrm{s}}$ porque a $\mathrm{q}^{\text {ta }}$ del dho papel me tiene pagados quios $\mathrm{Y}$ cinq ${ }^{\text {ta }}$ y dos $\mathrm{R}^{\mathrm{s}}$ que están respaldados. $\mathrm{M}^{\text {do }}$ se cobren lo que restare.

Declaro que Don Antonio de Muñoz, vo de Cuenca me está dev do sesenta y seis $m^{a}$ de tres años que vivió en unas casas que yo tenía en la dha ciu ${ }^{d} . M^{\text {do }}$ se cobren.

$\mathrm{m}^{\text {do }}$ que todos mis vestidos que se allasen al tiempo de mi fallecim ${ }^{\text {to }}$ se den $y$ entreguen a Xptoval Romero porque me encomiende a dios

$m^{\text {do }}$ que a Franc ${ }^{a}$ de Aro mi criada que ha muchos años que me sirve se le ajuste la $q^{\text {ta }}$ de lo que le estoy dev $^{\text {do }}$ de su salario como de otros gastos pequeños que ha echo por mi y de todo se le de satisfacción.

Asimismo, declaro que de diferentes quentas ajustadas que tube con la dha Franca de Aro la estoy dev do cinquenta ducados de Vellón. M do que mis testamentarios $y$ heros, de lo mexor parado de mis bienes la paguen la dha cant $^{\mathrm{d}} \mathrm{p}^{\mathrm{a}}$ descargo de mi conciencia.

$M^{\text {do }}$ que, a Theresa Romero, hija del dho Xpval Romero se le den todos los papeles, libros y estampas que del arte del pintor se hallasen en mi poder y assimismo, dos Piedras de moler colores una grande y otra pequeña y que se le entregue a su $\mathrm{P}^{\mathrm{a}}$ quando la susodha tome estado para que me encomiende a Dios.

$\mathrm{M}^{\text {do }}$ que asimismo se le den a la dha Theresa Romero una pintura de nra $\mathrm{S}$ con el Niño y un Ángel dando [...].

$M^{\text {do }}$ que se de asimismo a la dha Fran ca de Aro la cama en que la susodha duerme que se compone de la madera y cordeles, un colchón, un sergon, dos almuadas dos savanas y dos fracados. $Y$ pídele encomiende a Dios.

Yten $\mathrm{m}^{\text {do }}$ a Ju $\mathrm{Ju}^{\circ}$ Matheo una piedra grande de moler colores que tengo en $\mathrm{mi}$ poder para que me encomiende a Dios.

$Y P^{a}$ cumplir y pagar este mi testam ${ }^{\text {to }}$ las $m^{\text {das }} y$ legados en el contenido dexo y nombro por mis testamentarios y executores de el a Don Gil Pardo de Naxera $S^{\text {io }}$ de su magd en los $R^{s}$ descargos $Y$ al dho Don Antonio de Pedrossa 
y Molina y a qual quiera ymsolidum a los quales doy mi poder cumplido para que después de mis días entren en mis bienes y los bendan en almoneda o fuera della y cumplan y paguen este mi testam ${ }^{\text {to }}$ y lo en él contenido.

$Y$ de remanente que quedare de todos mis vienes, desechos $y$ acciones que tengo y me tocan y pertenezca dexo y nombro por mi heredera unibersal en todos ellos a Da Ma García Salmerón mi hija lex ${ }^{\text {ma }}$ y de Da Joana Millán mi mujr difunta y la dha hija es muj ${ }^{r}$ de Don Diego de Escals y Salcedo oydor Criminal dela $\mathrm{R}^{\prime}$ au ${ }^{d}$ balencia para que la susodha lo erede con la bendición de Dios y la mia, y la pido y encargo me encomiende a Dios.

Yten declaro que yo no tengo más vienes muebles ni Raíces mas que tan solam ${ }^{\text {te }}$ las pocas alaxas que tengo en mi quarto de las quales dándome Dios lug $^{r}$ dexare echa mem ${ }^{a}$ y ynventario por menor firmado de mi mano y en poder de uno dellos dhos mis testamos. Por la qual quiero que ese este pase como de Real y Verdaderamente estubiera a intentar en este mi testam ${ }^{\text {to }}$.

$Y$ revoco y anulo y doy por ninguno y de ningún balor ni efecto todos y quales $q^{a}$ testam $^{o s}$ cobdiziados y poderes que a y a dado $\mathrm{p}^{\mathrm{a}}$ testar mandar que a y a echo por escripto o de palabras que no quiero que balgan salvo este que hago y otorgo que dexo por mi testam ${ }^{\text {to }}$ Última y postrimera volunt ${ }^{\mathrm{d}}$. $Y$ en aquella via y forma que mas aya lugar de dro en testim ${ }^{\circ}$ de lo qual lo otorgo ansi el press $^{\text {te }}$ scrivano en la $\mathrm{V}^{\mathrm{a}}$ de $\mathrm{M}^{\mathrm{a}}$ a veinte $\mathrm{y}$ dos días del mes de otb de mill y seis ${ }^{\text {tos }}$ y setenta y tres años, siendo tgos Martín de Carate, Andrés Pardo, Joan Matheo, Antonio de Chindurca, Xptoval Romero Res ${ }^{\text {de }}$ tods en esta Corte. El otorgante que yo el press ${ }^{\text {te }}$ scriv $^{\text {no }}$ doy fee q conozco lo firmo.

Test $^{\text {do }}$ la em ${ }^{\text {do }}$ nra $S^{\text {ra }}$ entr ${ }^{\text {s }}$ dela.

Firmas de Cristóbal García Salmerón y Sebastián Carrillo. 
Fuentes documentales:

Archivo Histórico Provincial de Cuenca (AHPC)

P- 920, Francisco de Salazar, 1625, fol. 20-21v.

P- 1034, Juan del Castillo, 1643-1649, fol. 87-87v.

P-1071, Alonso González, 1657, fol. 736-737v.

Archivo Histórico de Protocolos de Madrid (AHPM)

T. 4215, Martín de Badarán, 1655-1666, fol. 754-754v.

T. 6248, Francisco Suárez y Rivera, 1650, fol. 231-231v.

T. 6543, Pedro de Castro, 1664, fol. 532.

T. 6944, Melchor Felipe de Baena Parada, 1651, fol. 131-131v.

T. 9301, Sebastián Carrillo, 1674, fol. 32-32v.

T. 9301, Sebastián Carrillo, 1673-1677, fol. 136-136v.

T. 9301, Sebastián Carrillo, 1673-1677, fol. 213-216.

T. 9349, Bonifacio de Robles, 1665, fol. 200-200v.

T. 9907, Simón Navarro, 1664-1667, fol. 38-39. 
Bibliografía:

Angulo Íñiguez y Pérez Sánchez 1972: Diego Angulo Íñiguez y Alfonso E. Pérez Sánchez, Historia de la pintura española. Escuela toledana de la primera mitad del siglo XVII, (Madrid: Instituto Diego Velázquez, 1972).

Barrio Moya 1994: José Luis Barrio Moya, "Algunas noticias sobre Cristóbal García Salmerón, pintor conquense del siglo XVII", en Tiempo y espacio en el arte: homenaje al profesor Antonio Bonet Correa, vol. II, (Madrid: Universidad Complutense, 1994), pp. 901-910.

Martín González 1993: Juan José Martín González, El artista en la sociedad española del siglo XVII, (Madrid: Cátedra, 1993).

Palomino 1746: Antonio Palomino de Castro y Velasco, Las ciudades, iglesias y conventos en España donde ay obras, de los pintores y estatuarios eminentes españoles, (Londres: Impresso por Henrique Woodfall, 1746).

Palomino 1947: Antonio Palomino de Castro y Velasco, El Museo Pictórico y Escala Óptica, (Madrid: M. Aguilar Editor, 1947).

Pérez Sánchez 2010: Alfonso E. Pérez Sánchez, Pintura barroca en España (1600-1750), (Madrid: Cátedra, 2010).

Ponz 1776: Antonio Ponz, Viage de España, en que se da noticia de las cosas más apreciables, y dignas de saberse, que hay en ella, Tomo V, (Madrid: Joachin Ibarra, 1776).

Revenga Domínguez 2002: Paula Revenga Domínguez, Pintura y sociedad en el Toledo barroco, (Toledo: Monografías 13, 2002).

Scals y Salcedo 1681: Diego de Scals y Salcedo, Origen, casa y familia de Scals o de la Scala, heredada en las montañas de el reyno de Valencia desde su conquista y sita en la antiquissima villa de Conzentayna, solar antiguo, y primitivo suyo y derivada legitimamente por linera recta de varón en varón de los Scalas príncipes y señores de Verona y Vicencia en Italia desde el año 1228 hasta el de 1681 con los servicios que ha hecho a la Real Corona que con su persona pone reverente a los reales pies de Su Magestad, (Valencia: Francisco Mestre, 1681).

Scals y Salcedo 1681: Diego de Scals y Salcedo, Zenotafio gentilicio, y parentación honoraria de glorias militares al árbol genealógico y chronologico historiado de la Casa de Scals o de la Scala en las montañas de el reyno de Valencia. Erigenle fieles, entallanle constantes y la instauran officiosas de los elados marmoles de la antiguedad en solemne remembranza de la familia, a la perpetua memoria de zenizas heroicas, illustradas, y redivivas, (Valencia: Francisco Mestre, 1681).

Recibido: 15/02/2021

Aceptado: 28/04/2021 